\title{
CC Chemokine Receptor 5 Targeted Nanoparticles Imaging the Progression and Regression of Atherosclerosis Using Positron Emission Tomography/Computed Tomography
}

Lisa Detering, ${ }^{\dagger \neq}{ }^{\dagger \neq}$ Allison Abdilla, ${ }^{\S,}$ Hannah P. Luehmann, ${ }^{\dagger}$ Jesse W. Williams, ${ }^{\#}$ LiHao Huang, ${ }^{\#}$ Deborah Sultan, ${ }^{\dagger}$ Andrew Elvington,,${ }^{*}$ Gyu Seong Heo, ${ }^{\dagger}$ Pamela K. Woodard, ${ }^{\dagger}$ Robert J. Gropler, ${ }^{\dagger}$ Gwendalyn J. Randolph, ${ }^{\#}$ Craig J. Hawker ${ }^{\S, *}$, and Yongjian Liư,**

${ }^{\dagger}$ Mallinckrodt Institute of Radiology, Washington University, St. Louis, Missouri 63110, United States

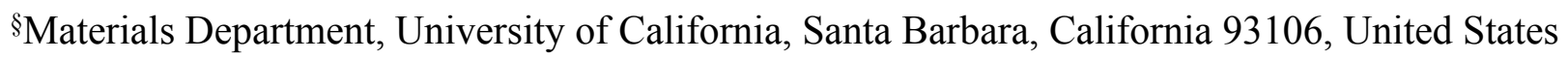
\#Department of Pathology and Immunology, Washington University, St. Louis, Missouri 63110, United States 
a Functional Monomers

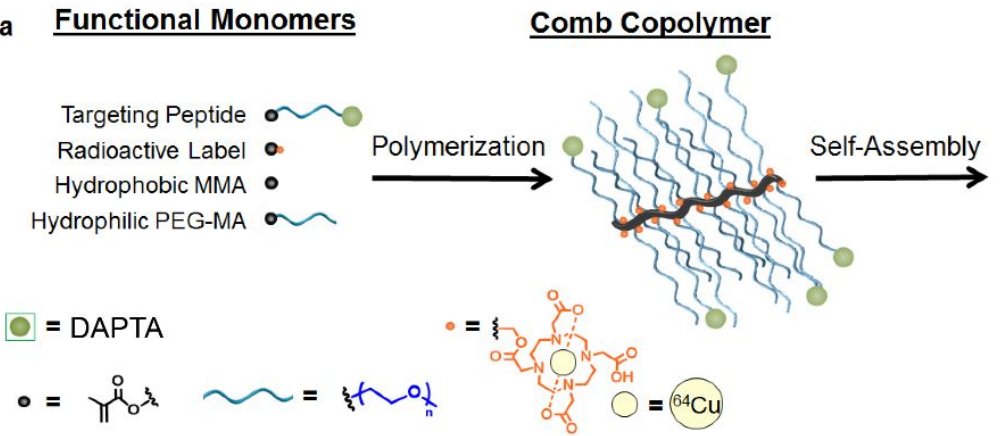

\section{Tailored Nanoparticles}

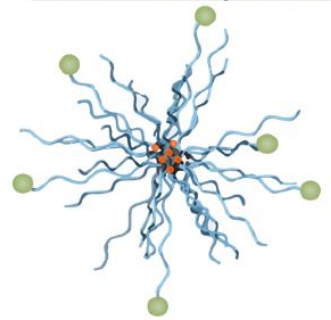
Biocompatible, targeted
imaging agent

\section{b}

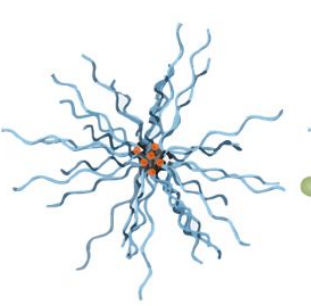

Comb

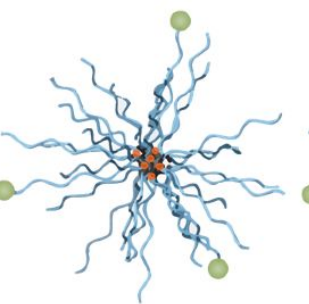

$10 \%$

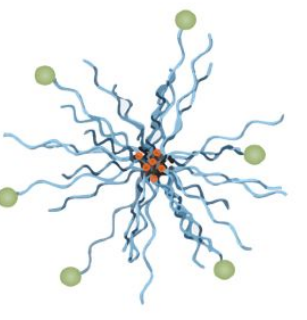

$25 \%$

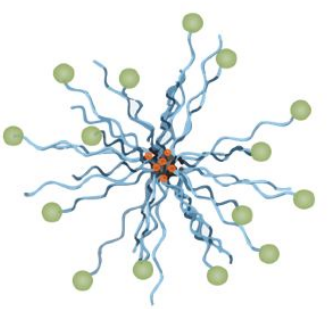

$40 \%$

\section{${ }^{64} \mathrm{Cu}$-DAPTA-Comb}

Figure S1. Synthetic scheme of $10 \%, 25 \%$, and $40 \%{ }^{64} \mathrm{Cu}$-DAPTA-Combs 

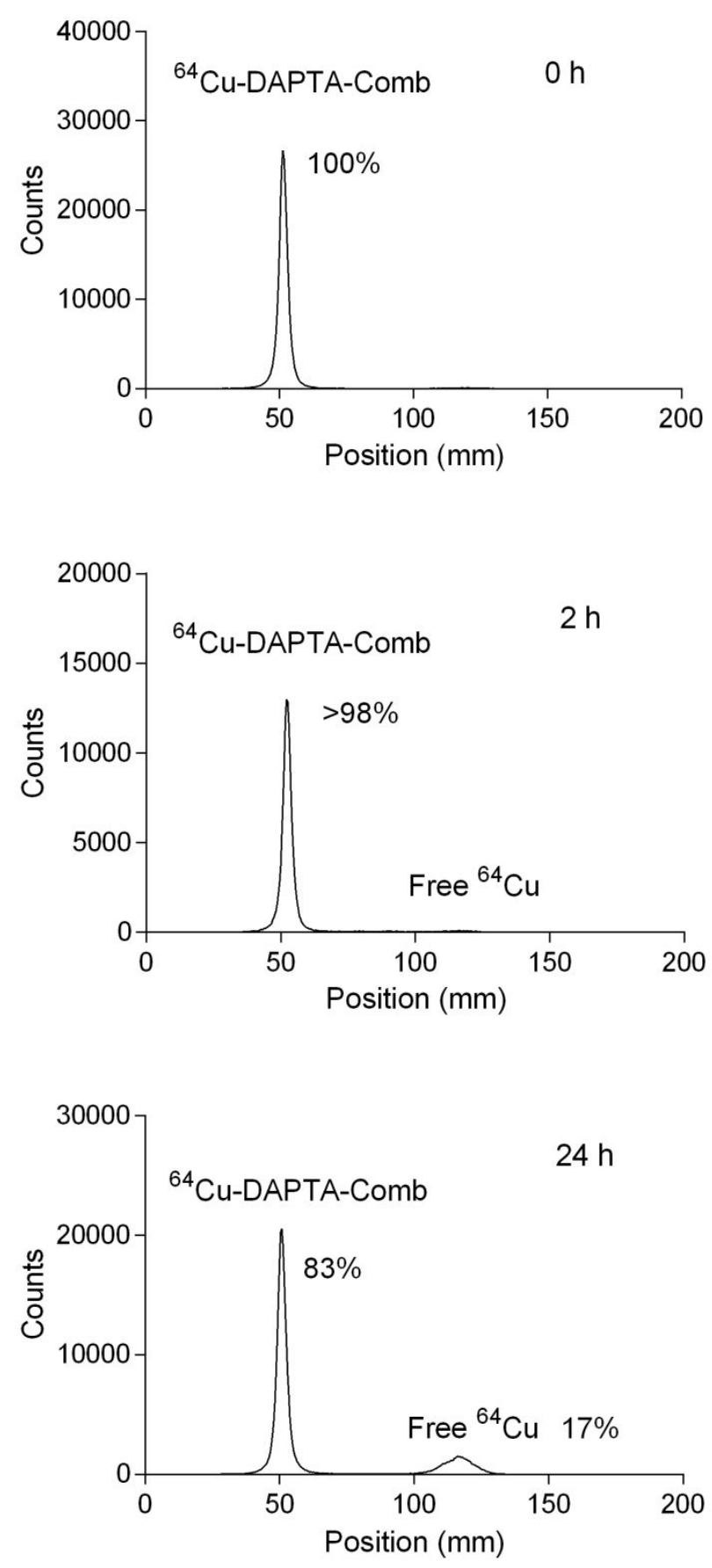

Figure S2. Mouse serum stability of $40 \%{ }^{64} \mathrm{Cu}$-DAPTA-Comb determined by radio-TLC at $1 \mathrm{~h}, 2 \mathrm{~h}$, and $24 \mathrm{~h}$ post incubation. 

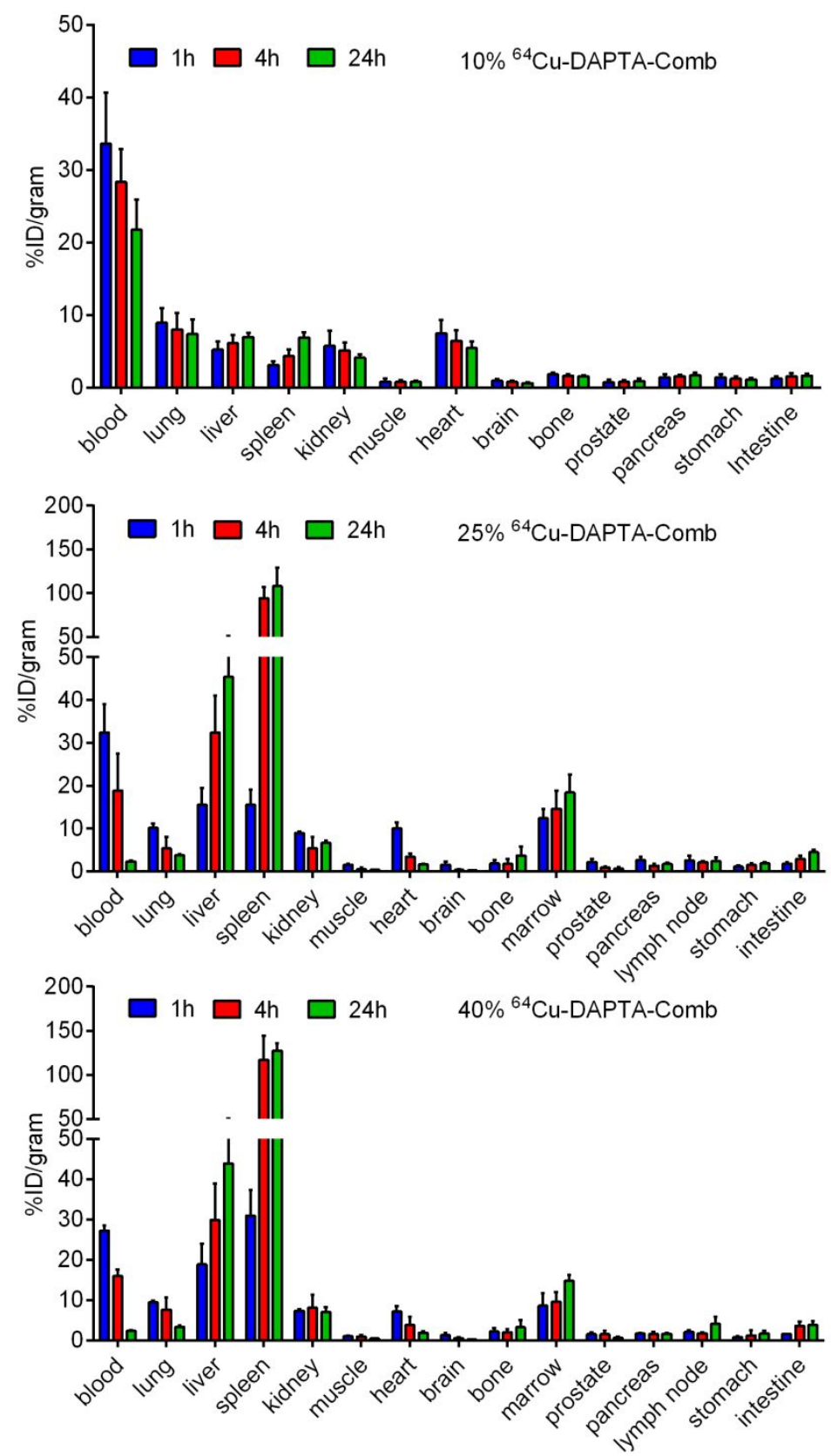

Figure S3. Biodistribution of $10 \%, 25 \%$, and $40 \%{ }^{64} \mathrm{Cu}-\mathrm{DAPTA}-\mathrm{Comb}$ in wild-type C57BL/6 mice ( $\mathrm{n}=4$ /group) at $1 \mathrm{~h}, 4 \mathrm{~h}$, and $24 \mathrm{~h}$ post-intravenous injection. 


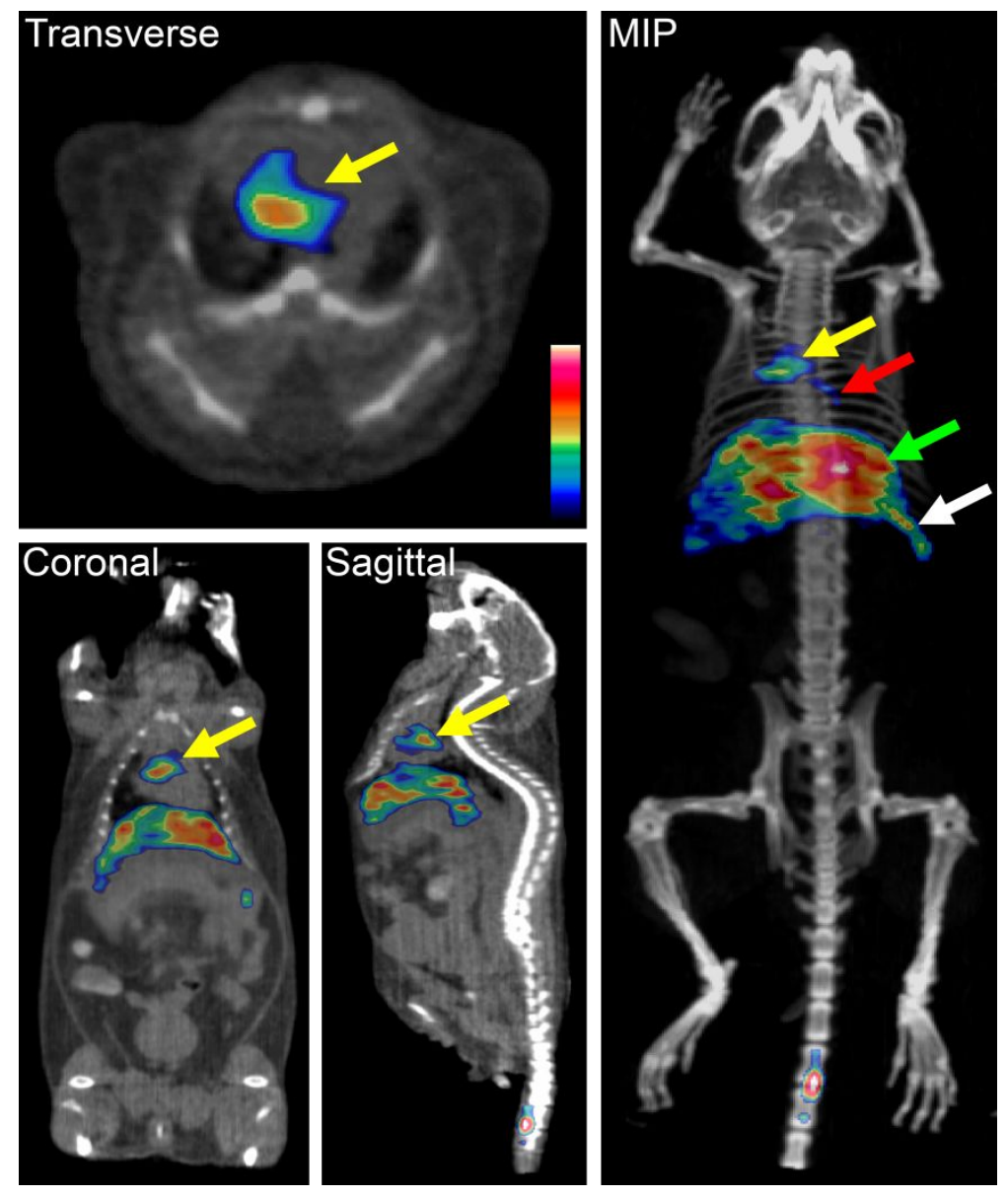

Figure S4. PET/CT images of $10 \%{ }^{64} \mathrm{Cu}-\mathrm{DAPTA}-\mathrm{Comb}$ in $\mathrm{ApoE}^{-/-}$mice at 8 weeks post $\mathrm{HFD}$ at $24 \mathrm{~h}$ post injection showing the uptake at aortic arch. Transverse, coronal, sagittal views and maximum intensity projection (MIP) image revealed tracer localization at aortic arch (yellow arrow). MIP image also showed little blood retention in the left ventricle of heart (red arrow) but high liver (green arrow) and spleen (white arrow) accumulation. 


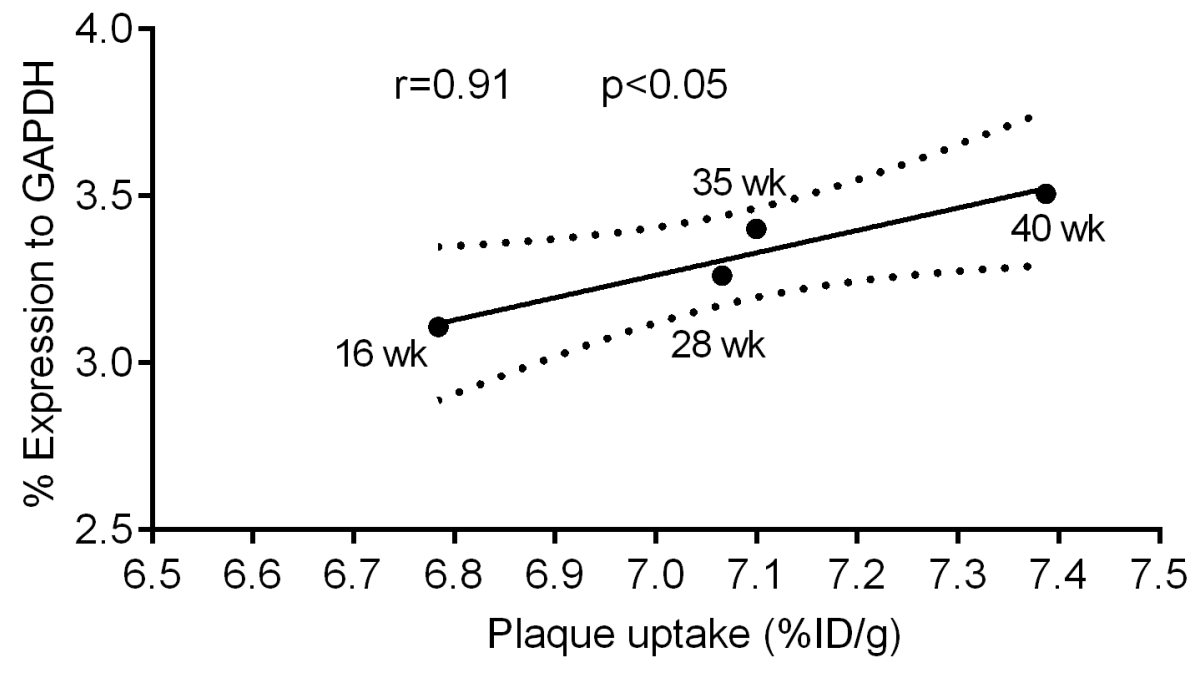

Figure S5. Association between $10 \%{ }^{64} \mathrm{Cu}$-DAPTA-Comb uptake in plaques at $16,28,35$, and 40 weeks post high fat diet and CCR5 RT-PCR data ( $\mathrm{n}=4-5 /$ time point) for aortic arteries of $\mathrm{ApoE}^{-/-}$mice. 


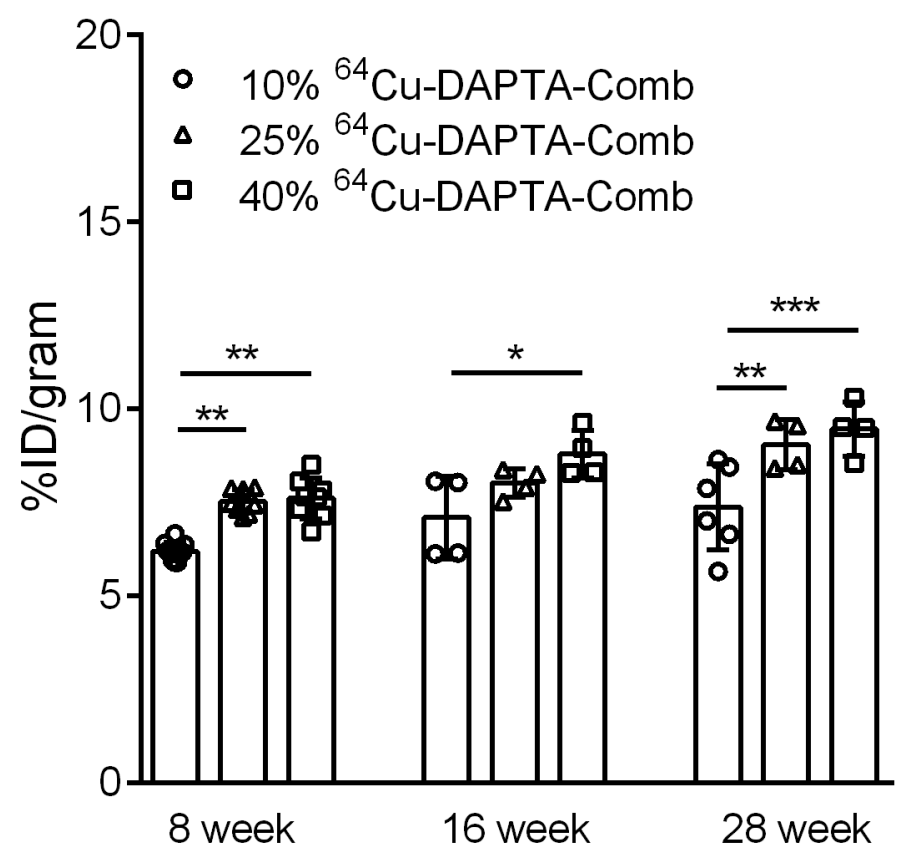

Figure S6. Summary of PET uptake of $10 \%, 25 \%$, and $40 \%{ }^{64} \mathrm{Cu}-\mathrm{DAPTA}-\mathrm{Comb}$ in ApoE $\mathrm{E}^{-/-}$mice at 8,16 and 28 weeks post high fat diet. $* \mathrm{p}<0.05, * * \mathrm{p}<0.01, * * * \mathrm{p}<0.001$ 